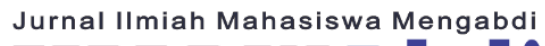 JIMAWAbdi :-8
}

p-ISSN: 2776-3099 ; e-ISSN: 2776-5261 DOI:10.32493

Jurnal Ilmiah Mahasiswa Mengabdi (JIMAWAbdi)

Volume 1 Nomor 1, April 2021 (43 - 46)

http://openjournal.unpam.ac.id/index.php/JMAb/index

\section{Pelatihan Membuat Perencanaan Bisnis (Business Plan) Dalam Meningkatkan Daya Saing UMKM Pada Skala Mikro}

\author{
Siti Ma'rifah', Faqihuddin², Farhan Nizam Firdaus ${ }^{3}$, M. Irsandy Tandia ${ }^{4}$, \\ Ila Mariska ${ }^{5}$, Anna Permatasari ${ }^{6}$ \\ ${ }^{123456}$ Program Studi Manajemen, Fakultas Ekonomi, Universitas Pamulang \\ marifahs77@gmail.com
}

Received 25 April 2021| Revised 26 April 2021 | Accepted 27 April 2021

*Korespondensi Penulis

\begin{abstract}
Abstrak
Tujuan Pengabdian Kepada Masyarakat (PKM) Mahasiswa ini adalah untuk memberikan pengetahuan dan pemahaman kepada anggota Pembinaan Kesejahteraan Keluarga (PKK) Cisauk yang beralamat di Jalan Griya Serpong Asri RT. 001 RW. 005 Des. Suradita Kec. Cisauk Kab. Tangerang 15343. Adapun Metode kegiatan ini adalah mendatangi Pembinaan Kesejahteraan Keluarga tersebut dan memberikan pelatihan serta diskusi mengenai Pelatihan Perencanaan Bisnis dalam meningkatkan daya saing UMKM. Hasil dari kegiatan tersebut adalah para peserta menjadi lebih mengerti tentang cara Perencanaan Bisnis di masa Pandemi Covid-19, sehingga di masa yang akan datang Para peserta dapat bersaing secara struktural dan dapat mengetahui langkah langkah yang efektif dalam ber-UMKM.
\end{abstract}

Kata Kunci: Perencanaan Bisnis; Studi Ekonomi

\begin{abstract}
The purpose of this Student Community Service (PKM) is to provide knowledge and understanding to members of the Cisauk Family Welfare Development (PKK) located on Jalan Griya Serpong Asri RT. 001 RW. 005 Des Suradita Kec. Cisauk Kab. Tangerang 15343. The method of this activity is to visit Family Welfare Development and provide training and discussion on Business Planning Training in increasing the competitiveness of UMKM. The result of this activity is that the participants are increasingly aware of how business planning was carried out during the Covid-19 Pandemic, so that in the future the participants can compete structurally and can see effective steps in UMKM.
\end{abstract}

Keywords: Business Planning; Economic Studies

\section{PENDAHULUAN}

UMKM merupakan tulang punggung perekonomian Indonesia. Berdasarkan data kementrian Koperasi dan UKM, sebanyak 98,7 usaha di Indonesia merupakan UMKM yang sudah menyerap $89,17 \%$ tenaga kerja saat ini. Dalam berusaha tidak cukup bila kita hanya memanfaatakan bekal keyakinana saja, namun diperlukan juga perencanaan bisnis (business plan). Khususnya dalam menjalankan usaha baru, karena tidak mungkin tanpa ada rencana terlebih dahulu sebelumnya. Bagaimanapun juga rencana harus ada walaupun sesederhana mungkin secara tertulis. Perencanaan yang tidak tertulis atau masih didalam pikiran tentu saja sudah ada, yang berisi tentang usaha apa yang akan dibuka, mengaoa memilih usaha dibidang ini, dimana lokasinya, darimana modal berasal, dan bagaimana pengelolaan sumber dayanya. Oleh karena itu, maka dibutuhkannya adanya perencanaan bisnis.

Peran business plan ini sangat bermanfaat bagi UMKM, karena dengan perencanaan bisnis ini maka UMKM tersebut dapat mengidentifikasi serta dapat memaarkan apasaja kebutuhan konsumen dan kebutuhan 
bagi UMKM tersebut untuk menganalisis dalam pencarian solusi dalam menggali potensi. Hal ini dilakukan untuk terciptanya inovasi baru dan memaksimalkan penggunaan sumber daya yang dimiliki oleh unit usaha serta dapat meminimalisir kerugian atau resiko yang akan di alami oleh kesitan UMKM ini.

Permasalahan UMKM yang biasanya dirasakan pada saat ini adalah bagaimana caranya menciptakan perencanaan bisnis yang baik, baik dari aspek SDM, manajemen, biaya produksi, maupun keuangan. Selain itu, perencanaan manajemen keuangan yang baik juga juga sangat berpengaruh dalam meningkatkan daya saing pelaku usaha kecil dan menengah (G.Kusjono, dkk: 2021)

Lalu, ditambah dengan kurangnya akan pengetahuan tentang bagaimana cara dalam pengembangan bisnis maupun penciptaan inovasi produk. Biasanya kegiatan produksi dan pemasaran dalam kegiatan UMKM ini masih tradisional sehingga mengakibatkan peluang usahanya menjadi kecil.

Berdasarkan dari uraian yang telah dijelaskan sebelumnya, maka perlu diadakannya sosialisasi serta pembelajaran mengenai pembuatan perencanaan bisnis (business plan) bagi para pelaku UMKM sehingga diharapkan dari kegiatan ini dapat berperan untuk menggali potensi yang ada sebanyak mungkin dari para pelaku UMKM. Dengan diadakannya sosialisasi dan pembelajaran mengenai perencanaan bisnis pada pelaku ekonomi kreatif dalam hal ini yang dimaksud adalah UMKM, dapat menjadi tolak ukur dari proses pengembangan dan pertumbuhan UMKM dan ekonomi kreatif.

\section{Tujuan PKM}

Adapun tujuan dari dilakukannya Pengabdian Kepada Masyarakat (PKM) ini yaitu sebagai berikut :

1. Memberikan pelatihan dan penyuluhan kepada individu ataupun pelaku usaha UMKM agar mereka dapat menyusun perencanaan dan pengelolaan usaha yang sedang dijalankan.
2. Membekali para pelaku UMKM agar memiliki pemahaman dan pengathuan tentang pentingnya perencanaan bisnis dan pengelolaan usaha yang tepat.

3. Dapat menyusun perencanaan dan pengelolaan usaha UMKM yang telah dijalankan maupun yang akan dijalankan.

\section{Business Plan}

Rencana bisnis atau business plan adalah pernyataan formal atas tujuan berdirinya sebuah bisnis, serta alasan mengapa pendirinya yakin bahwa tujuan dari usaha tersebut dapat dicapai, serta strategi atau rencana apa yang akan dijalankan untuk mencapai tujuan tersebut.

Menurut Hisrich, Peter (2008) "The Business Plan is a written document prepared by the entrepreneur that describe all the relevant external and internal element involves in starting a new venture". Business plan adalah dokumen tertulis dibuat oleh pengusaha yang menggambarkan semua informasi internal dan eksternal yang relevan.

Business plan adalah sebuah rancangan manajemen bisnis dari awal perintisan sampai bisnis terus berkembang. Business plan tidak hanya berguna ketika sebuah bisnis berjalan diawal-awal, namun berlaku pada saat bisnis mengalami proses yang begitu panjang. Menurut Megginson, Business plan merupakan suatu rencan tertulis yang memuat mini serta tujuan bisnis, cara kerja serta rincian keungan/permodalan lapisan para owner serta manajemen bagaimana cara menggapai tujuan bisnisnya. Jadi bisa ditarik kesimpulan bahwa business plan adalah sekumpulan dari rencanarencana dari sebuah bisnsi untuk menghadapi perkembangan dari sebuah bisnis.

Di dalam perencanaan bisnis perlu dilakukan analisis kelayakan Usaha, hal ini dikarenakan aspek utama dalam melakukan usaha pertama kali faktor kelayakan perlu diperhatikan dan merupakan hal yang cukup penting. Perencanaan usaha diperlukan dalam kegiatan bisnis yang akan dilakukan maupun yang sedang berjalan agar tetap berada dijalur yang benar sesuai dengan yang direncanakan. 


\section{METODE}

Dalam kegiatan ini kami mendatangi langsung ke pusat balai warga tempat Pembinaan Kesejahteraan Keluarga dan memberikan pembelajaran serta diskusi mengenai perencaan bisnis dengan metode presentasi materi menggunakan proyektor, diskusi dan Tanya jawab. Metode yang digunakan antara lain:

Tabel 1. Metode Kegiatan

\begin{tabular}{llll}
\hline No. & \multicolumn{1}{c}{ Peserta } & \multicolumn{1}{c}{ Permasalahan } & \multicolumn{1}{c}{ Solusi } \\
\hline 1 & Ibu-Ibu PKK & Masih banyak yang belum & Memberikan penyuluhan edukasi tentang \\
Griya & memahami arti penting dari & pentingnya Perencanaan Bisnis kepada para \\
& Serpong Asri & pusiness plan bagian & peserta kegiatan Pengabdian Kepada Masyarakat \\
& kegiatan UMKM. & (PKM). \\
\cline { 2 - 3 } & Strategi dan pengelolaan & Memberikan penjelasan tentang pentingnya paran \\
& sumber daya manusia yang & business plan walaupun pengelolaan SDM yang \\
& minim, sehingga merasa & masih kecil atau pada saat usaha yang baru \\
& tidak perlu membutuhkan & dirintis. Karena, dengan membuat business plan \\
& business plan. & ini secara matang maka usaha yang baru dirintis \\
& & akan memiliki tujuan yang jelas, entah dalam \\
& & jangka pendek ataupun jangka panjang.
\end{tabular}

\section{HASIL DAN PEMBAHASAN}

Tujuan dari adanya kegiatan pengabdian ini (PKM) adalah untuk mempersiapkan dan membekali pengetahuan kelompok atau para pelaku usaha, mengenai perancangan dan yang akan mereka jalankan. Sasarannya agar para ibu-ibu PKK ini mampu menciptakan dan mengelola bisnis secara mandiri dan berkesinambungan.

Beradasarkan hasil dari kegiatan PKM yang telah dilaksanakan oleh mahasiswa Program Studi Manajemen Universitas Pamulang, yang kegiatannya beralamat di Griya Serpong Asri RT. 001 RW. 005. Hasil dari penyuluhan dan sosialisasi ini menunjukkan bahwa dengan adanya pelatihan ini, para peserta dapat memiliki pengetahuan dan keterampilan baru yang praktis mengenai perencanaan bisnis suatu usaha atau business plan. Sehingga para peserta dapat termotivasi untuk membuat dan mempraktekkannya langsung dalam usaha mereka. implementasi mengenai perencanaan bisnis
1. Observasi: meninjau secara langsung peserta dan tempat lokasi kegiatan, serta beberapa kendala yang biasanya dihadapi, dari segi kebutuhan dan pemahaman masyarakat.

2. Pembelajaran: pemberian materi di lokasi yang didalamnya terdapat presentasi dan tanya jawab mengenai materi serta bagaimana mengimplementasikannya. jangka pendek ataupun jangka panjang.

\section{SIMPULAN}

Kesimpulan dari kegiata pelatihan ini antara lain:

1. Sangat membantu peserta pelatihan untuk mempersiapkan dan membekali pengetahuan kelompok atau para pelaku usaha.

2. Peserta pelatihan mengetahui mengenai perancangan dan implementasi mengenai perencanaan bisnis yang akan mereka jalankan sehingga mampu menciptakan dan mengelola bisnis secara mandiri dan berkesinambungan.

3. Peserta pelatihan memiliki pengetahuan dan keterampilan baru yang praktis mengenai perencanaan bisnis suatu usaha atau business plan.

\section{DAFTAR PUSTAKA}

Sukirno, Sadono. (2010). Makroekonomi: Teori Pengantar. Edisi Ketiga. Jakarta: PT. Raja Grasindo Perseda.

Afuah, Allan. (2004). Business Models: A Strategic Management Approach. New York: Mc Graw-Hill 
Kotler, Plilip. (2000). Manajemen Pemasaran.

Edisi Milenium. Jakarta: PT. Indeks Kelompok Gramedia

Kusjono, G., Sunanto, S., Azwina, D., Sulistyani, T., \& Lesmono, M. A. (2021). Pelatihan Manajemen Keuangan Sebagai Upaya Meningkatkan Daya Saing Umkm Kelurahan Benda Baru Pamulang. JPKM-Aphelion (Jurnal Pengabdian Kepada Masyarakat-Aphelion), 1(2), 224-233.

Bygrave, W.D. 1994. The Portable MBA in Entrepreneurship. New york: John Willey \& Sons, Inc

Hisrich, D Robbert dan Michael P Peters. 2008. Entrepreneurship. New York: McGraw Hill 